\title{
DE NARCISO A ORFEO. ALTERIDAD NARRATIVA Y ESPECTATORIAL EN TWIN PEAKS. THE RETURN DE DAVID LYNCH
}

\author{
FROM NARCISSUS TO ORPHEUS. \\ NARRATIVE AND SPECTATORIAL ALTERITY \\ IN DAVID LYNCH'S TWIN PEAKS.THE RETURN
}

Víctor ITURREGUI-MOTILOA

Universidad del País Vasco / Euskal Herriko Unibertsitatea viturregui001@ikasle.ehu.eus

\begin{abstract}
Resumen: Este artículo propone un estudio de la alteridad y la ficción en la serie Twin Peaks. The Return. Realizaremos un estudio de las decisiones formales y narrativas como procesos de significación, con el análisis fílmico y narratológico como herramienta. El trabajo se centra en la construcción del punto de vista y la identificación del espectador. El motivo de los mundos y figuras duplicadas desarrollado por David Lynch en su cine alcanza su acmé en la ficción televisiva. Además, estas ideas se materializan en la revisión de dos de los mitos clásicos sobre la relación con el Otro: Orfeo y Narciso.
\end{abstract}

Palabras clave: David Lynch. Twin Peaks. The Return. Imagen. Realidad. Doble. Orfeo. Narciso.

Abstract: This paper consists on a study of alterity and fiction in Twin Peaks. The Return. It will discuss the formal and narrative decisions as forms of signification, using film and narratological analysis. This research will pay attention to the construction of the point of view and to the identification of the spectator towards these images. The classical themes on lynchean films, such as alternative and duplicate worlds and figures, sublimate in TV fiction. Moreover, these ideas are represented by reinterpreting two myths related to the Other: Orpheus and Narcissus. 
Key Words: David Lynch. Twin Peaks. The Return. Image. Reality. Double. Orpheus. Narcissus.

\section{LOS DOS LADOS DE LA PANTALLA}

Este trabajo establece una conexión entre la figura clásica del doble fantasmal (doppelgänger) y la imagen como duplicado de la realidad en la serie de David Lynch Twin Peaks. The Return (2017). Se estudiarán las estrategias formales específicas que ponen en escena el doble y el Otro a partir de una sobrenatural narración detectivesca. Para ello Lynch trabaja con dos mitos fundacionales del arte occidental: Orfeo y Narciso. Su Orfeo visita ese otro mundo fantástico que parecer regir el real. Su Narciso podrá ver la ficción vista por los espectadores para intentar mejorarla desde dentro del espejo. En una era en la que el arte - especialmente el masivo y bajo demanda - funciona casi como una terapia evasiva, la fábula tramada en la obra de Lynch poco tiene de moraleja positiva. Si la experiencia estética de un espectador cualquiera no genera más que efectos psicológicos y sociales en ese receptor, las acciones de los personajes que se inmiscuyen en este relato acarrean unas consecuencias devastadoras en sus vidas y en las estructuras formales y narrativas que estos habitan.

Desde el amanecer del ser humano, su relación con la imagen, con la representación, ha sido, cuando menos, compleja. A grandes rasgos, las representaciones artísticas se consideran —despojadas de su valor económico o plástico - un apéndice liberador, un contrapeso que equilibra la negatividad de la existencia. Tanto de legado como de extensión de esa vida caduca, la imagen ha sido cargada con un sentido especular, una búsqueda de impresiones de realidad donde refugiarse. Doble proyección - de las imágenes captadas por la cámara en la pantalla y de las vivencias y fantasías del espectador sobre los personajes - que comporta una doble identificación - con el dispositivo y con las figuras-. En este sentido, la presencia de dobles en la literatura, el cine o la televisión comporta la formalización lingüística de ese instinto tan humano de no dejar de existir a toda costa. Lisa y llanamente, el doble fantasmal es la representación narrativo-formal del instinto de conservación, del miedo a la muerte, de la producción de imágenes que nos sobrevivan.

Twin Peaks es el campo de batalla de lo uno y de lo otro, de la 
superficie y la profundidad, del ser y el querer ser. Nada ni nadie es capaz de ser tal y como se supone que es; todo tiene una doble vida, desde las montañas hasta la malograda protagonista Laura Palmer. Los habitantes del pueblo, sus rostros, sus identidades, son destrozadas, alteradas, transmutadas, en un juego en el que las apariencias se sobreponen a la realidad. En esta ciudad, las mentiras y los misterios están a la orden del día. The Return representa los efectos de este deseo de entrar e intervenir en esa otredad que brindan las ficciones y las fantasías, con unos seres fantasmales que se mueven entre dos mundos y dos tiempos, a cada cual más hostil.

Como señala Fillol, las tres últimas películas de Lynch "trabajan sobre una estructura de doble mundo. [...] Hay un aparente mundo real que tiene una contracara imaginaria: la narración presenta primero una de esas dimensiones, que luego irá siendo contaminada y corroída por su reverso" (2016: 215). Sin embargo, en The Return se cambian las tornas. Estructurada a modo de Jano bifronte de lo real, estas dos faces del mundo son ahora simultáneas y la que en su cine se denominaría imaginaria, deviene en la ficción televisiva totalmente real. Además, la serialidad acentúa esta dualidad: mientras que sus filmes no dejan finales abiertos - aunque parezca lo contrario-, la historia de Twin Peaks es infinita y repetitiva. En este contexto, hay que tener en cuenta que las formas de consumo del cine y la televisión difieren sobremanera. Primero, por una diferencia de tamaños de la superficie que emite o recibe. Y segundo y más importante, porque las pantallas apagadas de los dispositivos de emisión reflejan todo aquello que tienen delante, al contrario que las lonas o paredes habituales en las salas de cine. Desde el psicoanálisis Slavoj Zizek apunta que toda "realidad social [...] solo puede existir si cuenta con el soporte de (al menos) dos fantasías, de dos tramas fantasmáticas" (2011: 160). Algo parejo ocurre en esta serie: no se entiende el funcionamiento lógico de la narración sin la interdependencia de dos realidades volátiles, entre el ser y el no-ser, el querer y el no-poder.

Por nuestra parte, este análisis extraerá esas ideas subyacentes en el texto a partir del análisis y la interpretación de las opciones audiovisuales y las estructuras narrativas puestas en juego. En otras palabras, se rastrearán las decisiones que toma Lynch por las cuales convierte un tema en una forma fílmica. La idea de la duplicación y la alteridad cristalizará, como ya hemos apuntado, en una escena correspondiente al penúltimo episodio: 
una sobreimpresión y un particular uso del punto de vista.

\section{2. ¿QUÉ PASA EN TWIN PEAKS?}

Twin Peaks (1990) relata el duelo de la localidad homónima ante el brutal asesinato de la joven Laura Palmer y la consiguiente investigación llevada a cabo por un peculiar agente del FBI. Un espíritu poseedor de cuerpos, Bob, se apodera, entre otros, primero de Laura (haciéndola caer en un mundo de autodestrucción), después de su padre (quien la asesina cegado e inconsciente por la ira del fantasma), y por último del agente Cooper, protagonista y principal sujeto de identificación con el espectador. En la secuela The Return (2017) el agente Cooper maligno que veíamos en el final de la segunda temporada es ahora un asesino que acecha a Twin Peaks. El verdadero Cooper se ha quedado encerrado en unas estancias cósmicas de donde debe escapar. Ambos comienzan una carrera por llegar al pueblo, el uno antes que el otro, en pos de salvarlo o destruirlo. Tras un sinfín de equívocos, obstáculos y digresiones, el Cooper bueno, con la ayuda del pueblo, vence a su némesis y al espíritu de Bob que lo poseía. Aunque todavía falta un asunto que resolver: recuperar a Laura. El meganarrador le muestra a Cooper esa falta para que la repare en consecuencia y restaure el happy ending ${ }^{1}$. En una travesía por el bosque, el héroe rescata a la Laura-del-pasado, pero es arrebatada literalmente de las manos del agente, probablemente por el espectro Bob. Cooper no se rinde y lo intenta una vez más: en esta ocasión transita a otra dimensión en la que algo falla. El detective encuentra a una mujer físicamente igual que Laura, pero con otra personalidad (parece haber olvidado quién es). Cooper, desesperado, ha fallado: se ha equivocado de tiempo, lugar y persona, y todo queda suspendido en una noche oscura en una solitaria calle.

\section{ORFEO Y NARCISO}

La temporada final de la serie elabora, especialmente en su último episodio, una relectura de los mitos de Orfeo y Narciso, que se hacen carne en el protagonista Dale Cooper. Las acciones narrativas de este

${ }^{1}$ Como apuntan Casetti y De Chio, el final feliz consiste en "realizar un recorrido hacia adelante para volver a la felicidad y encontrar la felicidad en el origen del recorrido" (1990: 216). 
personaje, así como la forma de representarlas en imágenes, modulan una interpretación no solo de la alteridad contenida en estas narraciones clásicas, sino que traslada estas preocupaciones a una concepción muy particular de la figura del espectador frente a la ficción. Así, en la clausura de Twin Peaks se explicita el siguiente principio temático: la ficción, ese mundo fantasmal creado a partir de la realidad, se hace posible a través de lo otro, desde una duplicación. Aquí nada funciona sin eso alternativo, sin esa réplica que amenaza. Figura recurrente en la obra de Lynch, lo doble - eso que no es ni lo uno ni lo otro- condiciona la evolución narrativa de sus personajes.

Por encima de todo lo demás, la conexión visual más evidente es la de Orfeo con el protagonista Cooper. Sin embargo, para respetar la secuencialidad que sigue el detective comenzaremos por indicar sus concomitancias con el narcisismo. Hay que acudir a la Metamorfosis de Ovidio para encontrar, con toda seguridad, el germen de la leyenda. La célebre historia de Narciso, en manos de Lynch, reverbera en la actitud del protagonista de la serie y del espectador que con éste se identifica. La clave de bóveda del mito de Narciso se localiza al entender que no es tanto el autoerotismo del reflejo como el darse "cuenta de que él es otro" (Ibáñez, 2016: 26) entre muchos más lo que le enamora. Conviene señalar que "la literatura narcisista ha profundizado entre otros asuntos antropológicos en el tema de la supervivencia tras la muerte y de la angustia de la muerte que proceden ambos de la contemplación del espejo" (Morin, 1974: 184). La ficción, innegable phármakon, instala en el espectador la ilusión de franquear la muerte, de atravesar el espejo, en busca de la inmortalidad simbólica (figura 1). Fuera de ella, el individuo trabaja por ajustar sus fantasías en la realidad. Sin embargo, las leyes vigentes dentro del discurso no son las mismas que fuera de él. Como con la lectura de un relato, lo real le obliga a investigar, tomárselo por su cuenta, actuar y arreglar (como todo detective observador que se precie). El deseo de pasar la prueba a toda costa (egoísmo) le oculta a Cooper el sentido final: que la muerte de Laura fue necesaria para el relato e irreversible. 


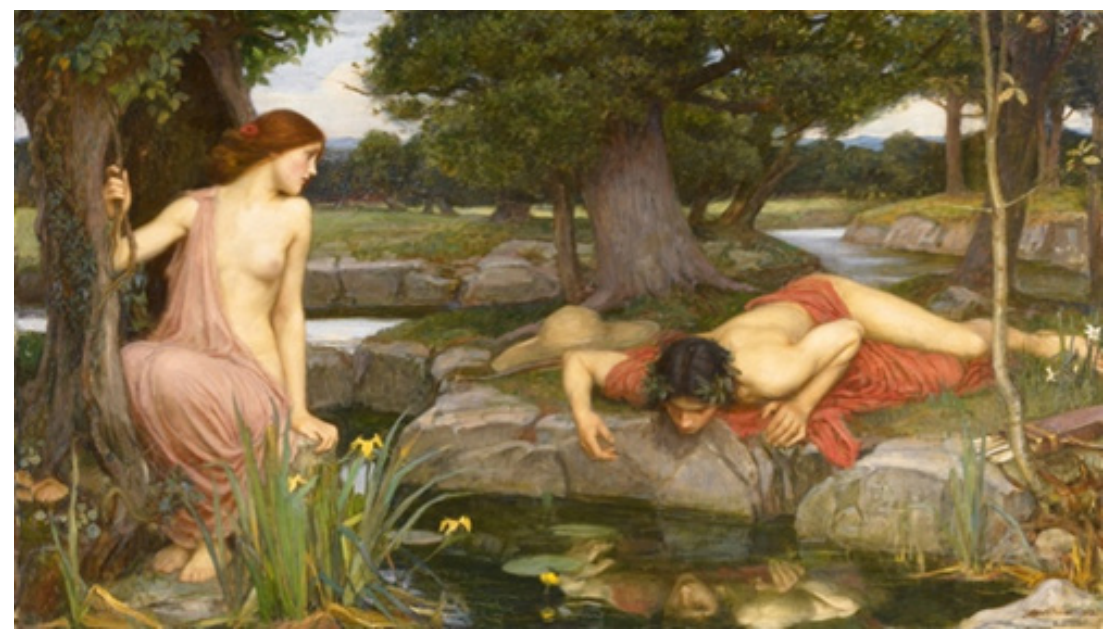

Figura 1. Eco y Narciso, de. W. Waterhouse (1903)

En lo que se refiere a la figura de Orfeo, aparte de transitar algunas de las fases del héroe monomítico sistematizadas por Joseph Campbell, Cooper cumple una serie de coincidencias con el cantor hijo de Eagro. Cuatro serían los puntos en común (Nieto, 2015: 14): en primer lugar, ambos tienen "un origen extranjero y dudoso"; Cooper aterriza en el pueblo como un alienígena y poco o nada sabemos de su pasado ${ }^{2}$; son mortales que emprenden sin problemas su "descenso al infierno"; los dos están dotados de una "capacidad extraordinaria que permite derrotar a seres monstruosos y así salvar a un grupo"; y por último, forman "parte de aventuras fuera de lo común", lejos de sus hogares y más largas de lo que esperaban. De idéntica forma, Eurídice encuentra su sosias en la asesinada Laura Palmer, quien, como la otra, muere dos veces, la segunda ocasión intentando ser revivida. A nadie escapará que ya Platón mencionó en El banquete, en boca de Diotima de Mantinea, la leyenda de Orfeo. Más destacables aún son los términos en los que se expresa: a Orfeo, "al que enviaron al Hades sin concederle lo que pedía. En vez de devolverle su esposa, a la que iba a buscar, no le enseñaron más que su fantasma" (2016: 241). Eurídice / Laura, al pertenecer al mundo de los muertos es ofrecida como una mera apariencia, como un espectro engañoso (figura 2).

Al margen de todo, el verdadero interés reside en la forma en que Lynch ensambla ambos mitos, confiriéndoles un nuevo sentido. Porque 
la impaciencia de Orfeo-Cooper, de Narciso-Cooper, se torna un reflejo, nunca mejor dicho, de cierta experiencia estética. En este contexto "la falta de quien quiere sustraerse a la ausencia de tiempo" (Blanchot, 2012: 163) es un ansia personal a la que el espectador es invitado. Y cuya asistencia puede dar al traste el goce estético, en forma de conclusión desoladora. Ya que lo que en definitiva trata de poner en forma Lynch es ese peligro (siempre hipotético, representativo) de la inmersión excesiva en las fantasías de la imagen.

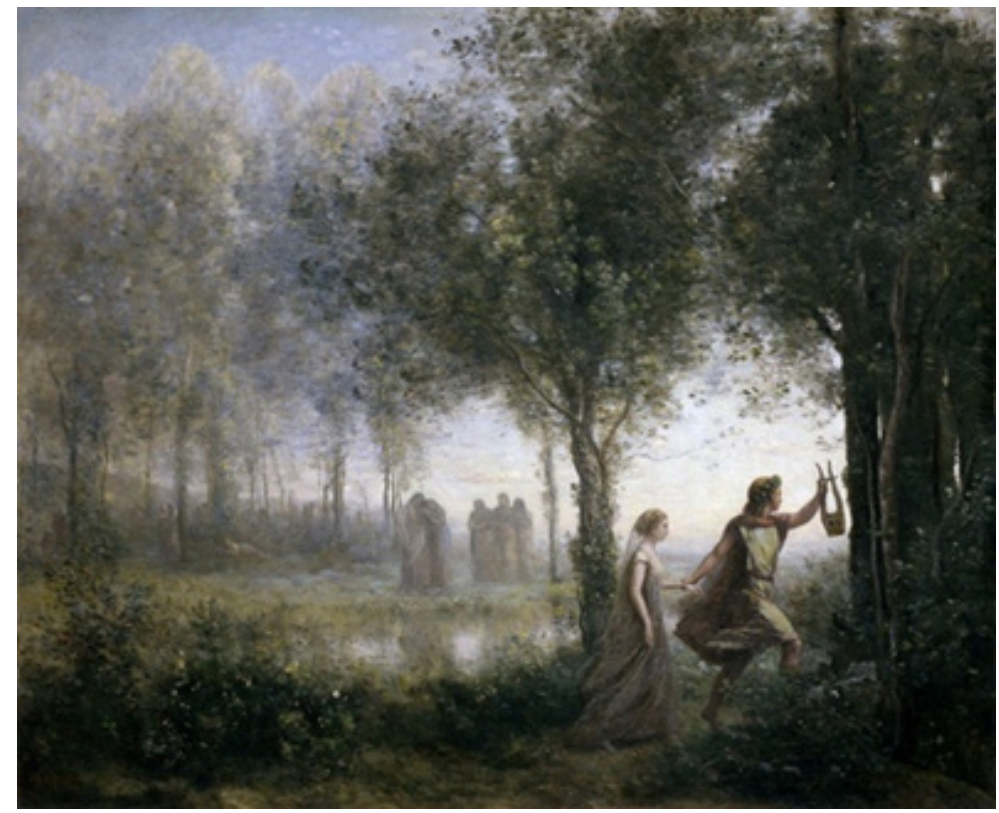

Figura 2. Orfeo conduciendo a Eurídice en el Infierno, de J. B. C. Corot (1861)

\section{DE ORFEO A NARCISO (Y VICEVERSA). ANÁLISIS FÍLMICO}

Una vez puestas sobre la mesa las ideas generales de nuestra argumentación y de la trama, es necesario aclarar algunos puntos concretos de esta última. Lynch ilustra la idea de la duplicación con una trama en la que ciertos personajes pueden modificar y alterar su universo como si de una película se tratara, con saltos temporales e incisos en la enunciación y 
en la narración. En una suerte de sala de montaje espacial se lleva a cabo una manipulación visual. Un gigante que ayudó en sueños en su momento al agente Cooper se apercibe de ciertos acontecimientos al verlos en una enorme pantalla de cine y responde a ellos con un metamontaje de imágenes. En la parte 17 se repite esta acción, pero en este caso es el Cooper maligno quien se vale del servicio para sus viles planes. Evidentemente, esas personas son construcciones lingüísticas escritas por un autor, pero su autonomía dista mucho de las limitaciones que definen a un personaje; la ficción no es operatoria en la realidad, pero las estructuras fantásticas pueden serlo en niveles diegéticos internos a ella.

\subsection{El espejo de la pantalla-mundo. Narciso}

Situado en un primer estrato, el narcisismo se refiere a la identificación interna de un personaje consigo mismo. En Twin Peaks se superponen dos niveles diegéticos: el inferior, que abarca la totalidad de la trama y la historia de la serie; y el superior, esbozado en la parte 8, que emerge en el último episodio y es una especie de reflejo sobrenatural del primero. En adición, señalaremos un segundo nexo persuasivo alojado en las cavidades más profundas del relato; esto es, el del espectador con las figuras diegéticas. En una escena decisiva se formaliza esta idea de la idea: una sobreimpresión funde el rostro del agente Cooper en primer plano con la ficción a la que él mismo pertenece, donde falta algo (figuras 5 y 6). Ese algo es, sin ir más lejos, un final feliz. Las imágenes del penúltimo episodio suponen una satisfacción para los personajes y el espectador, ya que, tras una tensión constante, el Bien ha conseguido vencer al Mal. Pero ¿de qué ha tratado siempre Twin Peaks? De la muerte de Laura Palmer, la gran ausente en esos planos generales que juntan a los protagonistas y abrochan el cinturón del final institucional. El agente Cooper es consciente de esa falta y el relato le ofrece la posibilidad de resolverla. Sabemos de antemano que el mundo en el que se inscribe lo que pasa en Twin Peaks no es el único conocido. Desde la primera temporada se nos muestran localizaciones como la Habitación Roja, donde ocurre gran parte de los hechos sobrenaturales. Ahora bien, en esta tercera entrega se desvela al espectador el verdadero poder e influencia que estos lugares tienen con, digamos, el mundo real. Ni más ni menos que el de la subordinación y 
la intervención operatoria: un mundo otro que tan pronto ayuda como entorpece a los personajes.

El agente Cooper ejecuta un cambio de posición en una compleja metalepsis. El protagonista es trasplantado por unos segundos de la diégesis interna al relato a una dimensión externa a este. Pasa a presenciar sus actos, como si un metanarrador le mostrase los acontecimientos (en exclusividad compartida con el espectador empírico) para actuar en consecuencia. Esto es, salvar a Laura, salvar el relato. En la escena frente al espejo que cerraba la segunda temporada (figura 3), "la mirada de Cooper nunca coincide realmente con el eje de visión del espectador, sino que se queda ligeramente escorada a la izquierda del encuadre. Hay una cierta distancia insalvable que bloquea la identificación" (Rodríguez, 2017: 139). En el filme-precuela Fuego camina conmigo la superposición de Cooper también estádesviada ${ }^{3}$ (figura 4). El agente no es consciente de que forma parte de un relato; está pensativo respecto a su función. Cooper es aún solo una figura de la diégesis primera. Apuntalemos esta idea con las palabras de Stoichita: "la relación frontal con el espejo es una relación consigo mismo, del mismo modo que la relación de perfil es, necesariamente, con el otro" (1999: 45).
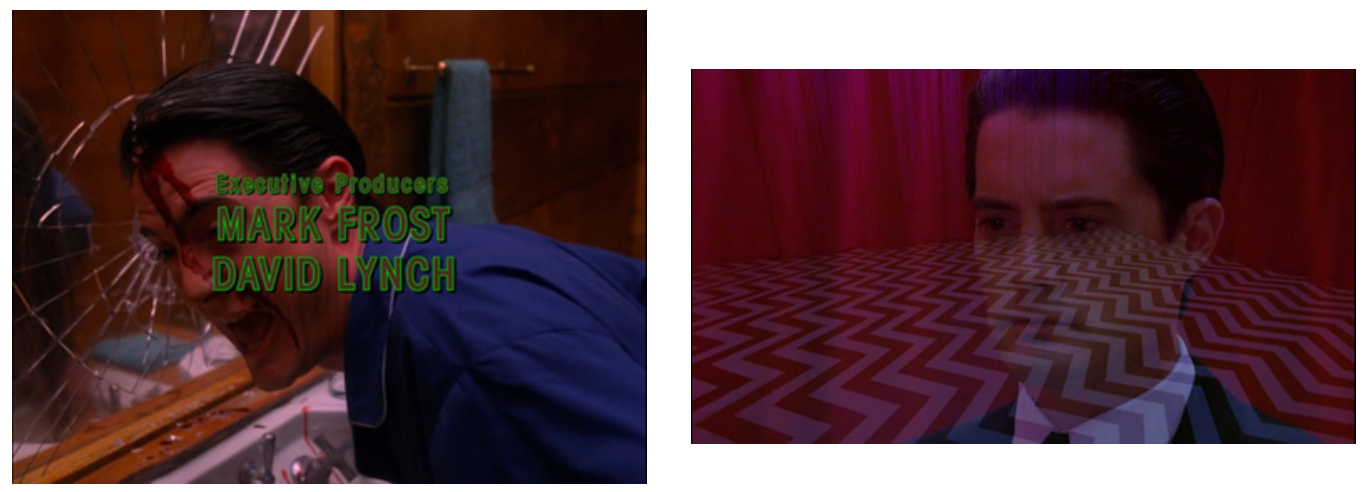

Figura 3. Twin Peaks, de David Lynch y Mark Frost (1990)

Figura 4. Twin Peaks. Fire walk with me, de David Lynch (1992)

A continuación, sostendremos que esta identificación está construida en pos de que el espectador disponga de un espacio habitable

\footnotetext{
${ }^{3}$ Composición habitual en la iconografía narcisista, tal y como ilustra el lienzo de Waterhouse mostrado más arriba.
} 
en el relato. En este sentido, el peaje para adquirir esa habitabilidad pasa por que el protagonista Cooper también goce de un lugar ideal en el que existir en el texto.

En The Return, Cooper mantiene esas funciones narrativas, pero se funde al final con el espectador-destinatario extradiscursivo: la mirada es frontal y contemplativa. El propio personaje sale de su diégesis y se transforma en un espectador intradiscursivo, endotópico. Este penúltimo episodio está creado para cerrar felizmente la trama que atañe al pueblo y la guerra entre el bien y el mal que se ha librado durante años. El Cooper superpuesto presencia estas imágenes desde la distancia, aunque él pertenezca a ellas (F5). Se da simultáneamente en el relato una narración de la que Cooper es el narratario a la vez que el enunciatario de ese "estar viendo". Cooper comparte el singular don de la ubicuidad con el espectador con el que se integra. Por esta razón Lynch resuelve "colocar la cámara en el lugar del héroe durante pequeños instantes con el fin de hacer compartir su punto de vista $y$, por tanto, permitir al espectador adaptarse a o mejor comprender sus sentimientos, su estado de ánimo" (Mitry, 1990: 64). Ese reflejo mete al espectador en su piel, lo predispone para asistir al último episodio. A partir de aquí, el Cooper superpuesto ya desaparece, porque ha visto el final únicamente de la historia primera (F6). Es ahora su deber cerrar el relato, hacer cumplir las obligaciones del monomito.
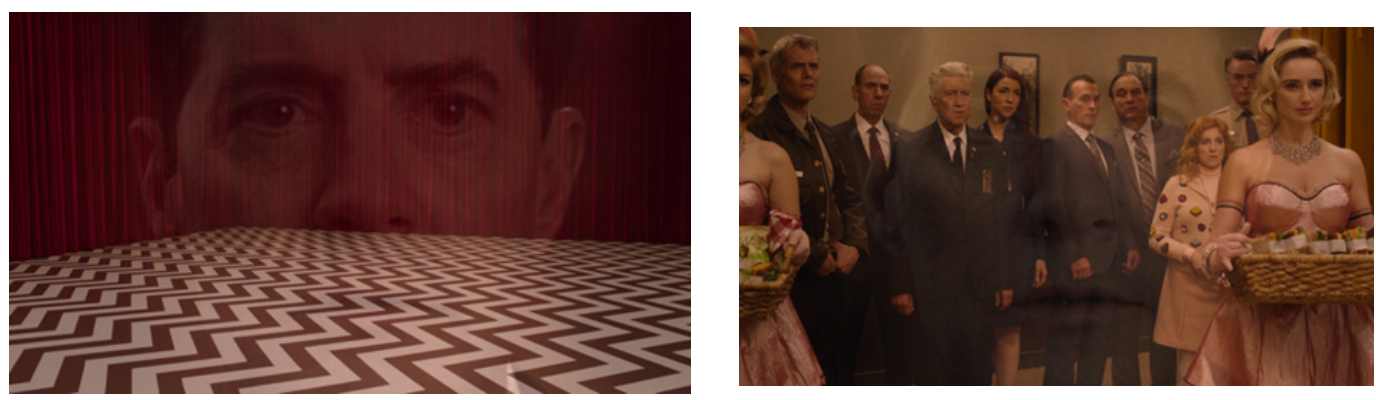

Figura 5. Twin Peaks. The Return, de David Lynch (2017)

Figura 6. Twin Peaks. The Return, de David Lynch (2017)

Diremos, con Gaudreault y Jost, que en un relato "se supone que lo que sucede realmente ante la cámara pertenece al universo del relato que la película me está mostrando" (2001: 93). ¿Qué desencadena Cooper? 
Primero, es sacado del encuadre y al reflejarse contradice ese mandamiento. Segundo, el personaje encarna una ocularización tan fuerte y violenta como empática. Aquí Cooper es espectador, narratario, enunciatario y destinatario. Dicho de otro modo: el detective, en una misma imagen especular, aparece como doble endotópico y como personaje exotópico (Stoichita, 1999: 115-116). Por extensión, esta escena trastoca asimismo la norma que dicta que los personajes, en tanto tales, no se aperciben de sus funciones textuales. Una propiedad cinematográfica que en este caso descarga su funcionalidad en favor de esa experiencia televisiva que venimos comentando.

Este desplazamiento de los agentes narrativos implica, a nuestro juicio, una mutación interna de papeles. Esto es, la conciencia del personaje comparte el saber del espectador real. Y esto conlleva una inversión por parte de Lynch de introducir, de facilitar el reconocimiento de quien consume el relato, similar a ese espejo oscuro del monitor televisivo apagado. El Cooper reflejado es una suerte de espectador fantasma que vive unos instantes para disfrutar desde fuera del final feliz y muere para viajar solo hacia la conclusión fatídica del relato, en virtud de la cual se consuma la adhesión casi total del lector empírico con el personaje. Desplazamiento endémico por el que "los espectadores [...] también alcanzan ese estado de transferencia, de empatía, de modo que "viven el rostro del protagonista como el propio suyo"” (Altuna, 2010: 72). Desiderio Blanco afirma que "la dimensión discursiva se juega siempre entre el enunciador y el enunciatario" (2003: 291). En consonancia, Gérard Genette, acerca de la narración en segunda persona, recalcará la singularidad de esta perspectiva del discurso, y su catalizador hacia la "identidad entre receptor y héroe" (1998: 92). Ambos asertos respaldan esta idea. El desplazamiento constituido en esta escena conjuga una forma de personalización que en una primera capa enuncia: el personaje es simultáneamente espectador, hace y mira. Ulteriormente, en un sentido metanarrativo, esta imagen nos brinda más información: no es él quien hace, sino tú, vosotros, él y tú, personaje y espectador, ambos en uno.

Cooper no solo está presente en el espacio diegético en el que tiene lugar la acción que le es mostrada, se encuentra en un segundo nivel indeterminado que se funde con el extradiegético por el efecto-reflejo de la superposición de planos. Se enuncia al mismo tiempo el campo y el contracampo (imaginado), el enunciatario implícito superpuesto con el 
enunciado, la narración con el narratario visual. Vemos al que mira, vemos cómo mira y lo que mira al mismo tiempo. Y todo ello formalizado de manera que nos haga creer que nosotros somos ese sujeto que mira.

Nos encontramos, entonces, con que un "enunciador 'obliga a hacer' a unos personajes la parte del narrador y del narratario respectivamente, es decir, les atribuye un papel y los hace actuar, los designa como sus encargados y los introduce en una misión concreta" (Casetti, 1989: 138). Este mandato de competencia sitúa a Cooper como un testigo activo, al vulnerar la regla de su programa narrativo. Si el testigo "es el que está predispuesto a mirar y, por tanto, aquel al que se le consiente ver, pero sin que tal mandato deba resultar explícito y sin que su función lo lleve a intervenir en lo que sucede" (Casetti, 1989: 80), Cooper acata y es reconocido positivamente, pero se le convoca una vez más.

\subsection{Arriba y abajo: viajes temporales y diegéticos. Orfeo}

Aquí es donde, concretamente, presenciamos el tránsito de Narciso a Orfeo: de la anagnórisis por la que asume la responsabilidad narrativa (mirarse en el espejo y reconocerse como el más capacitado, como el héroe), al viaje a los infiernos, a otro salto diegético en pos de modificar esas imágenes incompletas (rescatar a esa Eurídice que es Laura Palmer). Una transformación que entraña un cambio de estado: de héroe a demiurgo. Como podemos apreciar, la decisión de Cooper peca de inocente y su prurito bienintencionado deriva en una resolución devastadora.

En el último episodio no es el pasado el que se hace presente (flashback), sino un personaje el que invade el pasado. Cooper se traslada a la noche de la muerte de Laura. La banda de imagen se tiñe de blanco y negro ${ }^{4}$, estamos en otro tiempo, todavía oscuro. En la profundidad de un bosque, Laura se topa con Cooper (figuras 7 y 8), quien le espera casi como un espectro convocado para restaurar el orden del relato. Al parecer, el agente también ha corregido el orden moral y estético de la impoluta localidad, y la imagen adquiere color. De hecho, el metraje de la serie original reaparece influido visualmente por esta irrupción temporal. Mediante la edición y el montaje, la imagen se ensancha de los 4:3 a los

${ }^{4}$ Decisión tan maniquea como efectiva: las carga de un significado negativo y retroactivo, como si dijera que "cualquier tiempo pasado no tuvo por qué ser mejor". 
16:9, el cadáver de Laura desaparece de la playa y el pescador que encontró el cuerpo prosigue su rutina (figuras 9 y 10).
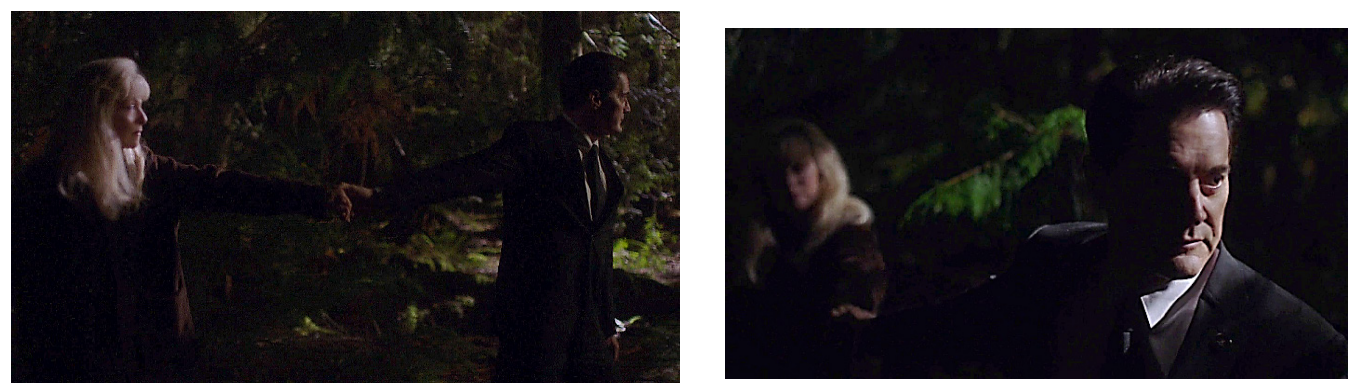

Figura 7. Twin Peaks. The Return, de David Lynch (2017)

Figura 8. Twin Peaks. The Return, de David Lynch (2017)
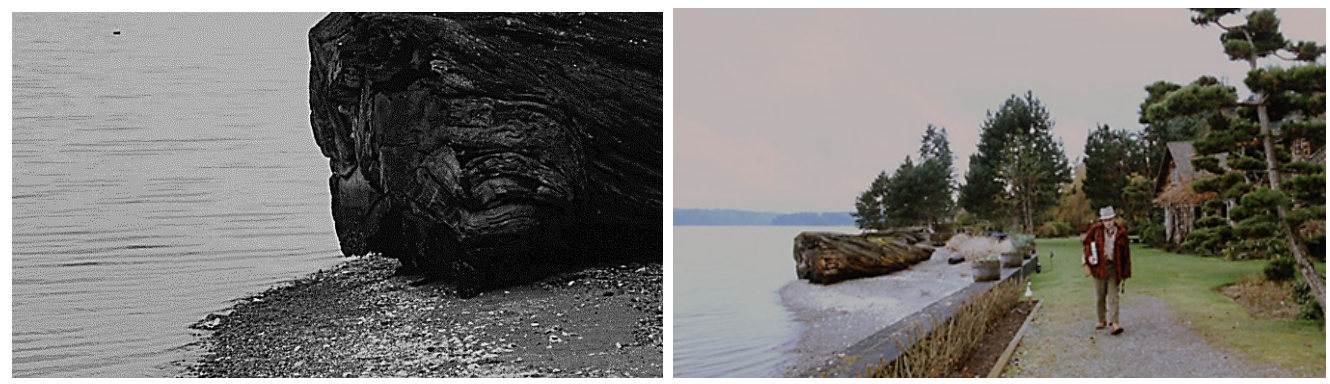

Figura 9. Twin Peaks. The Return, de David Lynch (2017)

Figura 10. Twin Peaks. The Return, de David Lynch (2017)

Cogidos de la mano, recorren lentamente el sendero bajo los árboles. Por un momento nos hallamos frente a una clausura perfecta, el punto culminante de una tortuosa odisea por el averno. Un sinuoso raccord de miradas produce un desfase con lo que sucede a continuación. Cooper vuelve la cabeza para asegurarse de que todo va bien (figura 11). Como Orfeo y Eurídice, en ese giro reside su error. Con un suave travelling horizontal que sigue a las manos aún juntas (figura 12), el encuadre corta esta unión gestual y la cámara desplazada nos desvela la separación en fuera de campo (como ese lugar indefinido e imposible desde el que vio 
su reflejo). Esa mirada salvífica al Otro no provoca sino su condena. El resto es de todos conocido: el segundo rescate de Laura resulta aún más catastrófico.
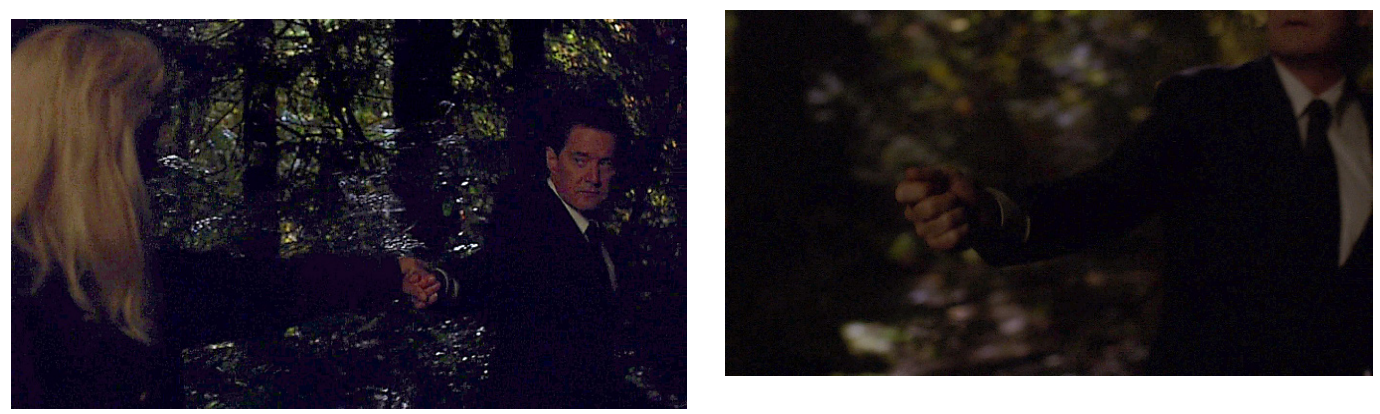

Figura 11. Twin Peaks. The Return, de David Lynch (2017)

Figura 12. Twin Peaks. The Return, de David Lynch (2017)

\section{LA VISTA Y EL TACTO. CONCLUSIONES}

En definitiva, lo que está en juego en Twin Peaks y en su recepción estética es la supervivencia simbólica ante la desaparición biológica. Ilustremos esta idea: los personajes de las dos primeras temporadas sufren con el visionado de una telenovela romántica que en The Return no existe (ya tenemos otra historia paralela, real y operatoria). Así se acentúa que en el núcleo de esta población regurgita - como espectadores- un deseo de reemplazar la realidad por su doble que sustenta la alteridad contemporánea frente a las ficciones. Lynch se vale del motivo icónico del espejo tanto de aparato de desapropiación alucinatoria de el mismo, como de materialización de una visión ideal que el sujeto reflejado imagina en el otro. Esto también puede traducirse en la concepción de la imagen como fantasma o reflejo de la realidad, esto es, de la visión idealizada, en detrimento de un mundo real que se rechaza por imperfecto.

Cooper, al verse afuera y adentro de su estructura discursiva, se siente un fantasma. Se genera el efecto de que una figura de la ficción sale de ella para convertirse en un espectador y ver el reflejo del narciso fundido con la imagen a la que pertenece. Empero, al mismo tiempo quiere desligarse de ella para arreglarla. Porque en ese plano general conjunto de 
todo el pueblo hay una ausencia: la de Laura, solo falta ella para que todo sea perfecto. Y hay que salir de ahí para solucionarlo. De lo que se desprende un corolario: la ausencia, el hueco a ocupar en toda representación, en todo trauma, es necesaria e imperturbable.

El espectador, como Dale Cooper, salva este obstáculo especular: “el espejo me muestra lo que sin él no puedo ver, pero jamás veré el reverso de las figuras reflejadas. Aunque el mundo especular es perfecto, solo me ofrece un punto de vista posible" (Aumont, 2009: 86). La imagen en movimiento busca corregir la casi perfecta ilusión del espejo, multiplicando los puntos de vista y las formas de ver / mirar. A saber, los mecanismos de identificación que hemos analizado. A través de estas manipulaciones expresivas el autor da su visión de la relación espectador-personaje, de la ficción-realidad, de los finales felices y de la recepción patémica de los espectadores (especialmente, los de los pequeños monitores). Recordemos que esta es una obra de televisión: en la pantalla del cine no existe reflejo, pero en el monitor o en otro dispositivo menor, si se apaga la emisión, el espectador podrá ver su rostro en primer plano. Estas imágenes nos dicen: "se mira, pero no se toca". O "se toca, pero no se mira". Quien se sienta frente a la televisión solo puede sentirse Narciso y nunca Orfeo; para ello tendría que pertenecer a la raza de seres fantásticos lyncheanos que rebasan lo real, o ser un ente ficticio. Y la única forma de salir de la realidad, por mucho mal que ésta inflija, parecen decirnos las imágenes de Twin Peaks, es pasando, como Orfeo, como Cooper, por las puertas del infierno.

\section{REFERENCIAS BIBLIOGRÁFICAS}

ALTUNA, B. (2010). Una historia moral del rostro. Valencia: Pre-Textos. AUMONT, J. (2009). Matière d'images, redux. París: Éditions de la Différence.

BLANCHOT, M. (2012). El espacio literario. Barcelona: Paidós.

BLANCO, D. (2003). Semiótica del texto fílmico. Lima: Universidad de Lima.

CASETTI, F. (1989). El film y su espectador. Madrid: Cátedra.

CASETTI, F. y DI CHIO, F. (1990). Análisis del film. Barcelona: Paidós. FILLOL, S. (2016). Historias de la desaparición. El cine desde Franz Kafka, Jacques Tourneur y David Lynch. Santander: Shangrila. 
GAUDREAULT, A. y JOST, F. (2001). El relato cinematográfico. Barcelona: Paidós.

GENETTE, G. (1998). Nuevo discurso del relato. Madrid: Cátedra.

IBÁÑEZ, A. (2016). A través del espejo. Girona: Atalanta.

MITRY, J. (1990). La semiología en tela de juicio (cine y lenguaje). Madrid: Akal.

MORIN, E. (1974). El hombre y la muerte. Barcelona: Kairós.

PLATÓN (2012). "El banquete". En Diálogos, 223-283. Madrid: Gredos. RODRÍGUEZ, A. (2017). "Hacer filosofía en Twin Peaks: mundo, existencia, belleza". En Regreso a Twin Peaks, D. Lynch et alii, 137-159. Madrid: Errata Naturae.

STOICHITA, V.I. (1999). Breve historia de la sombra. Madrid: Siruela.

ŽIŽEK, S. (2011). El acoso de las fantasías. Madrid: Akal.

Recibido el 2 de marzo de 2020.

Aceptado el 15 de abril de 2020. 